\title{
Spatial distribution and accessibility to public sector tertiary care teaching hospitals: case study from Pakistan
}

Naeem A. Malik ${ }^{1}$ and Masood A. Shaikh ${ }^{2}$

${ }^{1}$ Institute of Geo-Information and Earth Observation, PMAS Arid Agriculture University, Rawalpindi, Pakistan. ${ }^{2}$ Independent consultant, Karachi, Pakistan. (Correspondence to: Masood Ali Shaikh: masoodaliı@yahoo.com).

\begin{abstract}
Background: Public sector provision of health care services is important for addressing health morbidity and mortality burden for population health in developing countries like Pakistan. Physical accessibility and spatial distribution of healthcare facilities affect their utilization for improving population health.

Aims: This study aimed to analyze the spatial distribution of five public sector, tertiary care, teaching, general hospitals in the city of Lahore, Pakistan.

Methods: The point locations of all five hospitals were obtained from Google Earth. While the vector road network file was downloaded from the OpenStreetMap website. GIS software ArcGIS 10.5 and the Network Analyst extension were used for processing, analysis and mapping. The Lahore city shapefiles and the hospital point locations were projected to ensure correct spatial distance analysis.

Results: The five hospitals are located in the northeastern and east-central parts of Lahore. Most of the Lahore "towns" (administrative subdivisions) are either partially or completely covered by the 12-kilometre buffer as well as the 12-kilometre service area around these five selected hospitals. However, either the 12-kilometre buffer or service area did not cover large swaths of Wagha, Nishtar, and Iqbal towns.

Conclusions: Availability of geographic and attribute data on road network and population characteristics would facilitate planning for allocating locations for new health care facilities based on utilitarian principles.

Keywords: hospitals, accessibility, geographic information systems, spatial analysis, Pakistan

Citation: Malik NA; Shaikh MA. Spatial distribtion and accessibility to public sector tertiary care teaching hospitals: case study from Pakistan. East

Mediterr Health J. 2019;25(6):431-434. https://doi.org/10.26719/emhj.18.049

Received: $18 / 07 / 17$; accepted: 01/11/17

Copyright $\odot$ World Health Organization (WHO) 2019. Some rights reserved. This work is available under the CC BY-NC-SA 3.0 IGO license (https:// creativecommons.org/licenses/by-nc-sa/3.o/igo).
\end{abstract}

\section{Introduction}

Physical accessibility and spatial distribution of healthcare services influence their effective utilization for improving health and reducing morbidity and mortality burden $(1,2)$. In low- and middle-income countries, ability to pay for health care services, especially specialized and tertiary care services, poses a significant financial burden on the people hailing from the low to middle-income strata. Hence, provision of health care services by the public sector is a crucial factor in addressing the health morbidity and mortality burden for population health (3). Many families in Pakistan use public sector tertiary care hospitals affiliated with medical colleges and universities as a relatively affordable source of quality specialized health care.

Several spatial and non-spatial factors impinge upon utilization of health care services (4-6). Spatial factors influencing adequate spatial accessibility entail monetary costs associated with travel, travel time, and ease of physical accessibility to the health facilities (5). Spatial accessibility is quantified by straight line and network-based distances, among other methods (5). There is only one study on spatial accessibility to tertiary care, teaching, public sector, general hospitals in
Pakistan, using geographic information systems (GIS) and network analysis in Karachi (7), while another study from Islamabad looked at all health facilities and clinics in terms of their proximity to road network (8).

Lahore is the second largest city in Pakistan, in terms of population, and will be the country's second megacity by the year 2030 (9). Health policy-makers need to allocate locations of future public sector tertiary care teaching hospitals that would ensure maximum spatial accessibility to a given city's general population with minimal traversing of physical distances. The objectives of this study were to model the spatial accessibility to public sector, teaching, tertiary care, general hospitals in Lahore, using buffers and road network-based service areas.

\section{Methods}

The five public sector, teaching, general hospitals in Lahore are: Ganga Ram hospital, Jinnah hospital, Mao Hospital, Services Hospitals, and Sheikh Zayed Hospital, and were selected for spatial accessibility analysis. The point locations of all five hospitals, i.e. latitude and longitude ( $\mathrm{X}$ and $\mathrm{Y}$ ) coordinates of these hospitals, were obtained 
from Google Earth. While the vector road network file was downloaded from the OpenStreetMap website, for Pakistan (10). GIS analysis software ArcGIS 10.5 and the Network Analyst extension (Environmental Systems Research Institute [ESRI], Redlands, CA, USA) were used for processing, analysis and mapping.

Using the Lahore city boundary shapefile, the road network was extracted/clipped from the Pakistan road network downloaded from OpenStreetMap, and Lahore city road network shapefile was created. The Lahore city shapefiles and the hospital point locations were projected using Equidistant projection to ensure correct spatial distance analysis.

Three, six, nine, and 12-kilometre distance based buffers were drawn around the five hospitals. Next, three, six, nine, and 12-kilometre distance-based service areas around the five hospitals on a road network were created. The following rules and conditions for creating service areas using Network Analyst model were specified. Using the road network shapefile for Lahore city, a road network was built in the Network Analyst extension of ArcGIS program, as prerequisite for creating service areas. All five hospital point locations were collectively added next, as network analysis objects. The service areas were created with the ArcGIS's 'Network Analyst' extension, using 'Any Vertex' connectivity policy, while ignoring the elevation and direction of travel permitted on the roads in terms of one-way or two-way traffic flow.

Service areas were not trimmed, but buffers and service areas for the five hospitals were dissolved to depict an overall accessibility to any of the five hospitals in the city.

\section{Results}

All five hospitals are located in the northeastern and east-central parts of Lahore. Figure 1 shows the point locations of all five hospitals as well as all the "towns" of Lahore, along with their union councils (UCs). For spatial accessibility analysis, we used three, six, nine, and

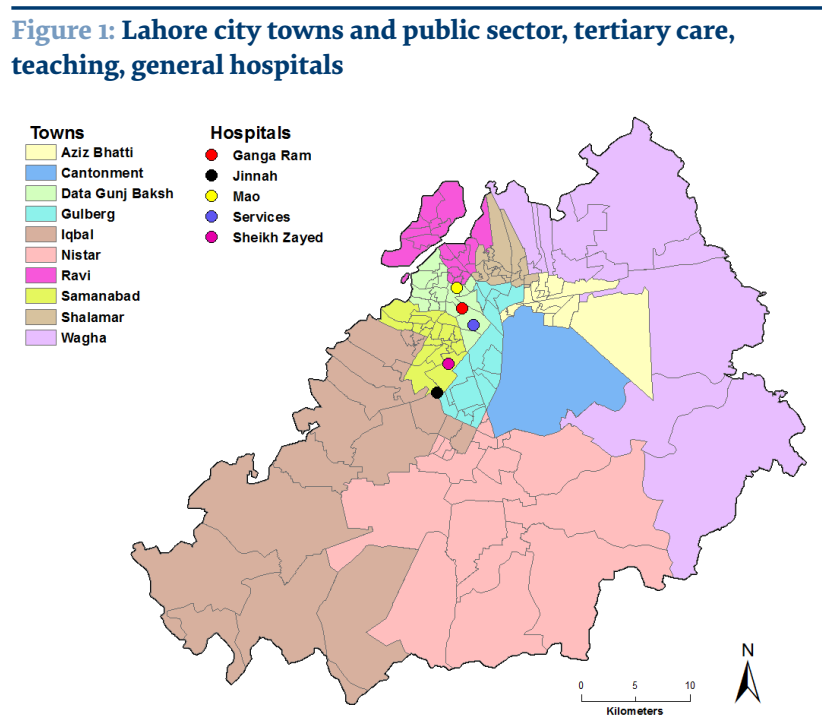

Figure 2: Buffers around public sector, tertiary care, teaching, general hospitals in Lahore

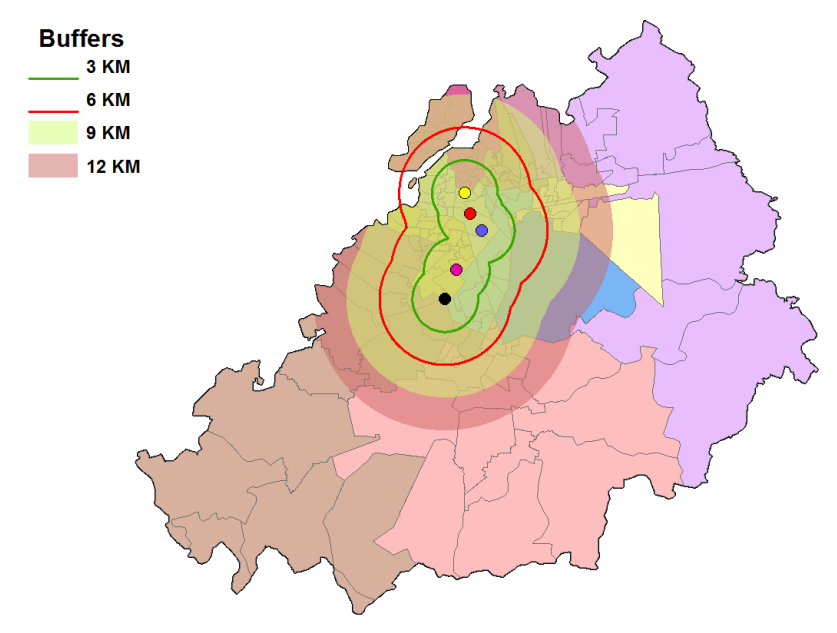

Figure 3: Service areas around public sector, tertiary care, teaching, general hospitals in Lahore

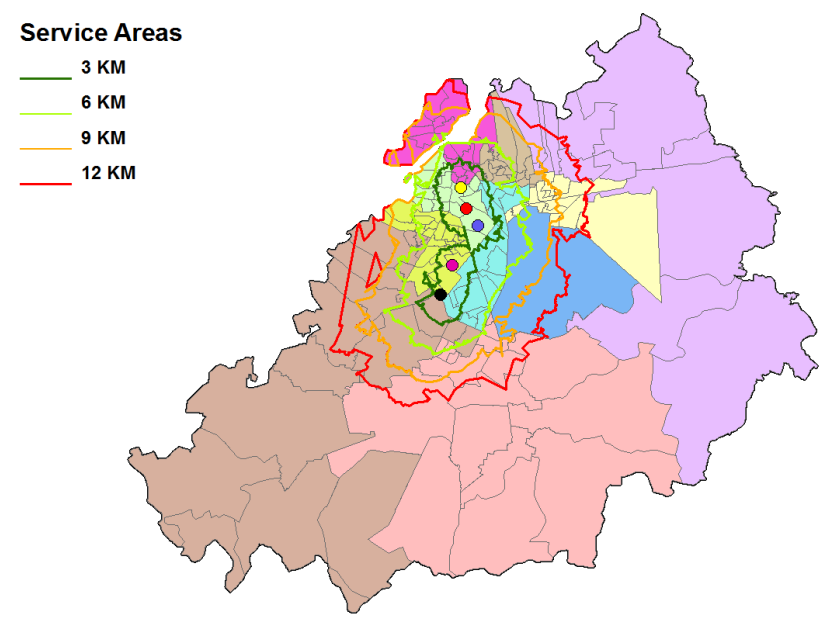

12-kilometre buffers and service areas. Buffers are based on straight line (Euclidean) distances around hospital point locations, while service areas comprise road network-based distance, i.e. all accessible roads leading to the point locations of hospitals.

Figure 2 shows the straight line distance based three, six, nine, and 12-kilometre based buffers around the five hospitals, while Figure 3 shows the three, six, nine, and 12-kilometre based service areas around the five hospitals. The buffer and service area maps depict which towns and UCs of Lahore are either entirely or partially covered/accessible within specified distances around the five hospitals. All towns were either partially or fully accessible within the 12-kilometre buffer as well as service area. However, large parts of Iqbal, Wagha, and Nishtar districts were neither covered by the 12-kilometre buffer nor service area.

\section{Discussion}

In this study we analyzed the spatial distribution of five public sector, tertiary care, teaching general hospitals in the city of Lahore, Pakistan. Results show that these five hospitals are located in the northeastern and east-central 
parts of Lahore. Most of the Lahore towns (administrative subdivisions) in Lahore are either partially or completely covered by the 12-kilometre buffer as well as the 12-kilometre service area around these five selected hospitals. However, either the 12-kilometre buffer or service area did not cover large swaths of Wagha, Nishtar, and Iqbal towns.

Although we created distance-based service areas around the five selected hospitals, depending upon availability of pertinent data, GIS also enables creation of service areas based upon travel time, and travel cost as well. Additionally, availability of information on population size and its breakdown in terms of sex and age would also enable calculation of number of people having access to selected hospitals. This would also help in determining spatial accessibility for the specific population groups including children women of childbearing age, and the elderly.

We downloaded Lahore road network data from a website where volunteers create such data, which is then made available in the public domain. This data, although quite useful in its own right, nonetheless does have limitations of completeness in terms of factoring elevations, underpasses/overpasses, direction of travel allowed on road segments, and permissible speed limits, and cost associated with travel on the roads. Without this information, appropriate spatial modelling with time and cost are not viable options. As data on direction of travel allowed on roads and on elevation are not available, our results are close approximations of distance based service areas. Data on residents by towns and UCs were also not available, and would have more clearly indicated the number of people having access to these selected hospitals within specified distances.

The only other study from Karachi, Sindh province, highlighted similar concerns of limited GIS and population data availability (7). This study also reported clustering of public sector teaching, and tertiary care general hospitals in lower southwestern part of the Karachi. While in the current study we found all five hospitals to be clustered in the northeastern and eastcentral parts of Lahore. Similarly, as in the Karachi study, our research concludes spatial accessibility to most parts of Lahore's administrative subdivisions.

\section{Conclusion}

There is a need to create/add data on direction of travel, speed limits, elevations, travel time, and travel cost, for the road network in future studies in order to strengthen and develop models on spatial accessibility to health facilities using time, cost and distance impedance correctly. Additionally, with the new census findings yet to be released, availability of data on population size and profile by various administrative subdivisions in the country would afford the opportunity for health policy-makers to determine spatial accessibility by population size and to plan for allocating new healthcare facilities locations based on utilitarian principles, in addition to ensuring health equity in terms of spatial accessibility to health care services.

Future spatial accessibility studies need to determine accessibility of primary and secondary and other tertiary care public sector health facilities, as well as private sector health facilities, to better gauge the populations/city residents accessibility to healthcare. Finally, the need for creating and making more detailed GIS data, including population distribution by geographic subdivisions, available to researchers in Pakistan are imperative for better health services planning.

Funding: None.

Competing interests: None declared.

\section{Répartition spatiale et accessibilité des hôpitaux universitaires de soins tertiaires du secteur public : étude de cas au Pakistan}

\section{Résumé}

Contexte : La prestation de services de santé par le secteur public est importante pour faire face à la charge de morbidité et de mortalité dans les pays en développement tels que le Pakistan. L'accessibilité physique et la répartition spatiale des établissements de santé influent sur leur utilisation pour améliorer la santé de la population.

Objectifs : La présente étude visait à analyser la répartition spatiale de cinq hôpitaux publics, de soins tertiaires, universitaires et généraux, de la ville de Lahore au Pakistan.

Méthodes : La localisation des cinq hôpitaux a été obtenue au moyen de Google Earth. Par contre, le fichier du réseau routier vectoriel a été téléchargé depuis le site OpenStreetMap. Le logiciel SIG ArcGIS 10.5 et l'extension Network Analyst ont été utilisés pour le traitement, l'analyse et la cartographie. Les fichiers de forme de la ville de Lahore et l'emplacement des points d'hôpital ont été projetés pour assurer une analyse spatiale correcte de la distance.

Résultats : Les cinq hôpitaux sont situés dans le nord-est et le centre-est de Lahore. La plupart des circonscriptions de Lahore sont partiellement ou totalement couvertes par la zone tampon de douze kilomètres ainsi que par la zone de service de douze kilomètres autour de ces cinq hôpitaux sélectionnés. Toutefois, ni la zone tampon ni la zone de service ne couvrait de larges surfaces des villes de Wagha, Nishtar et Iqbal.

Conclusions : La disponibilité de données géographiques et d'attributs sur le réseau routier et les caractéristiques de la population faciliterait la planification de l'allocation des emplacements des nouveaux établissements de soins de santé selon des principes utilitaires. 
التوزيع المكاني للمستشفيات التعليمية للرعاية الثالثية التابعة للقطاع العام وإمكانية الوصول إليها: دراسة حالة من باكستان نعيم مالك، مسعود شيخ الخلاصة

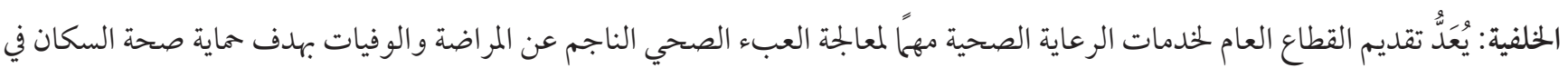

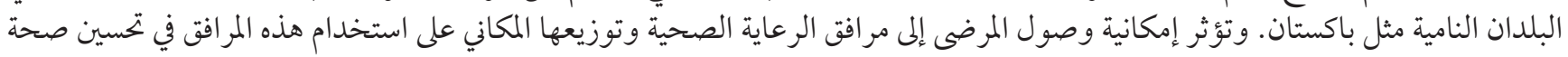
السكان.

الأهداف: هدفت هذه الدراسة إلى تحليل التوزيع المكاني لخمسة مستشفيات تعليمية عامة للرعاية الثالثية تابعة للقطاع العام في مدينة لاهور، باكستان.

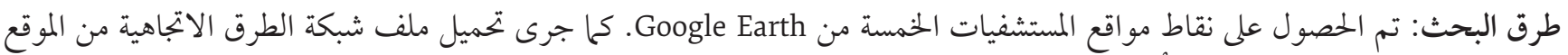

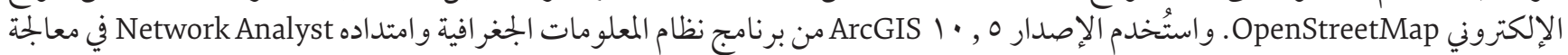

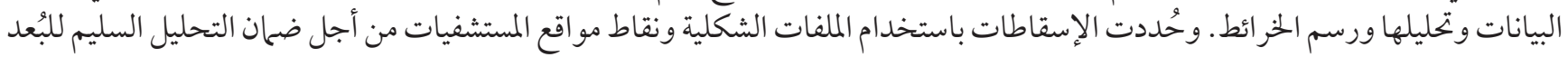
المكاني.

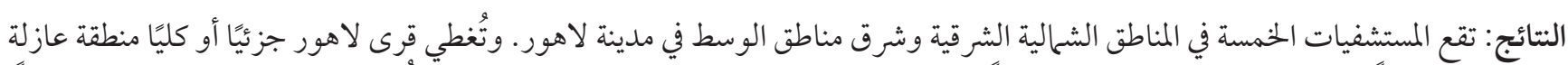

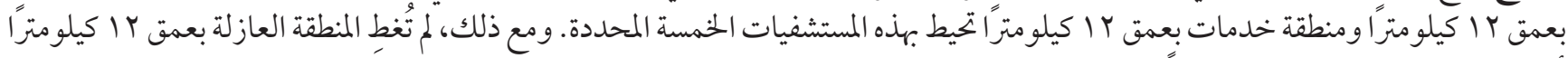

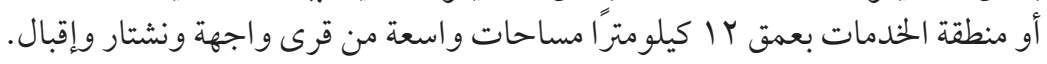

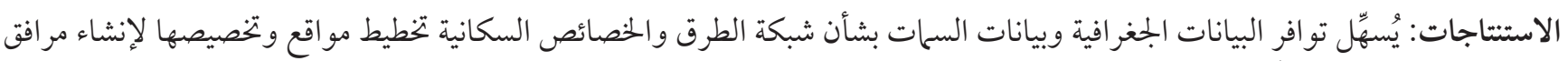
رعاية صحية جديدة استنادًا إلى المبادئ النفعية.

\section{References}

1. Biswas RK, Kabir E. Influence of distance between residence and health facilities on non-communicable diseases: An assessment over hypertension and diabetes in Bangladesh. PLoS One. 2017 May 18;12(5):e0177027. http://dx.doi.org/10.1371/journal. pone. 0177027

2. Seymour JW, Polsky DE, Brown EJ, Barbu CM, Grande D. The Role of Community Health Centers in Reducing Racial Disparities in Spatial Access to Primary Care. J Prim Care Community Health. 2017 Jul;8(3):147-52. http://dx.doi.org/10.1177/2150131917699029

3. Basu S, Andrews J, Kishore S, Panjabi R, Stuckler D. Comparative performance of private and public healthcare systems in lowand middle-income countries: a systematic review. PLoS Med. 2012;9(6):e1001244. http://dx.doi.org/10.1371/journal.pmed.1001244

4. Comber AJ, Brunsdon C, Radburn R. A spatial analysis of variations in health access: linking geography, socio-economic status and access perceptions. Int J Health Geogr. 2011 Jul 25;10(1):44. http://dx.doi.org/10.1186/1476-072X-10-44

5. Delamater PL, Messina JP, Shortridge AM, Grady SC. Measuring geographic access to health care: raster and network-based methods. Int J Health Geogr. 2012;11(1):15-18. http://dx.doi.org/10.1186/1476-072X-11-15

6. Goudge J, Gilson L, Russell S, Gumede T, Mills A. Affordability, availability and acceptability barriers to health care for the chronically ill: longitudinal case studies from South Africa. BMC Health Serv Res. 2009 May 9;9(1):75. http://dx.doi.org/10.1186/14726963-9-75

7. Shaikh MA, Ali MS. Spatial distribution and accessibility to public sector tertiary care teaching hospitals in Karachi: A Geographic Information Systems application. J Pak Med Assoc. 2016 Jul;66(7):889-92.

8. Shaikh MA. Spatial distribution of health facilities in Islamabad, Pakistan. East Mediterr Health J. 2013 Jan 9;19 Suppl 3:213-5. http://dx.doi.org/10.26719/2013.19.Supp3.S213

9. Pakistan Population. (http://www.worldometers.info/world-population/pakistan-population/, accessed 12 June, 2017).

10. OpenStreetMap (https://www.openstreetmap.org/\#map=11/31.9402/36.0750, accessed 12 June, 2017). 